\section{A publicidade como suporte pedagógico: a questão da discriminação por idade na publicidade da Sukita ${ }^{1}$}

\section{RESUMO}

A pesquisa que empreendemos durante 0 primeiro semestre de 2001 teve como objeto as percepções de mensagem publicitária (refrigerante Sukita) por alunos de segundo ano de Ensino Médio, durante exposição e debate em sala de aula. Esse estudo tinha como objetivo primeiro a verificação da pertinência do uso de uma publicidade como suporte pedagógico para discussão de um tema transversal (discriminação em função da idade). A análise dos dados registrados aponta para uma tendência, por parte dos alunos, de manifestação espontânea pouco crítica em relação ao modelo "socialmente autorizado" de abordagem erótico-afetiva proposto indiretamente pela mensagem publicitária.

\section{ABSTRACT \\ This article reports some of the findings of a study about an advertising campaign of the soft drink Sukita and the age discrimination theme it exploited, according the opinions expressed by second-year high school students surveyed for that research. \\ PALAVRAS-CHAVE (KEY WORDS) \\ - Publicidade (Advertising) \\ - Grounded theory \\ - Discriminação por idade (Age discrimination)}

Clóvis de Barros Filho

Professor da Faculdade Cásper Líbero e da ECA-USP
1 Introdução

Justificativa da linha de pesquisa

Apesar do espaço que os meios de comunicação ocupam na experiência de qualquer aluno, a mídia ainda não está integrada à grade curricular das escolas. A dificuldade reside em inserir, na educação formal, um objeto de estudo que rivaliza com a escola pelo monopólio tendencial da produção legítima de sentido, da interpretação socialmente aceita do real.

Reside também no fato de que o currículo escolar não se resume num acervo de conteúdos de saber. A grade curricular dá fundamento a um conjunto de esquemas sociais ligados à organização da sociedade e às suas necessidades (Durkheim), determinando a organização legítima do tempo e do espaço e facultando a "racionalidade econômica e a racionalidade política"2.

Dessa forma, a escola, através de seus conteúdos curriculares, participa do controle coletivo ${ }^{3}$, definindo a representação socialmente dominante de inteligência e divisão do trabalho. Essas prerrogativas, no entanto, dependem da legitimidade da instituição escolar, isto é, da indiscutibilidade da competência social que lhe é conferida para assegurar um determinado tipo de aprendizado social ${ }^{4}$. 
A perda progressiva dessa legitimidade institucional ensejou dúvida sobre os conteúdos curriculares e sobre o monopólio escolar de sua elaboração. A erosão desse reconhecimento social se traduziu, nas salas de aula, por reações dos alunos às regras disciplinares, conteúdos e atividades pedagógicas consideradas impertinentes.

Se em algum momento da história da instituição escolar o que era ensinado em sala de aula, por sê-lo, justificava seu aprendizado, hoje o aluno recebe, avalia e julga a mensagem pedagógica em função, sobretudo, de referenciais interiorizados alhures, ou seja, regras e critérios definidos por instâncias de socialização paraescolares.

Além desses referenciais, o conhecimento anterior, construído em educação formal ou não, revela-se como variável essencial desse julgamento, bem como da compreensão da mensagem escolar. Assim, "a relação das informações novas com as informações antigas é acompanhada de operações de tratamento - tais como a seleção, a categorização, a transformação, o ordenamento das informações -, operações tanto mais custosas quanto mais pobre for a base coginitva"s.

Dessa forma, a identificação, em um determinado universo escolar, dos referencias cognitivos, avaliativos e afetivos comuns aos alunos e a conseqüente definição de um repertório presumido comum dos mesmos devem ser exigência prioritária da atividade docente. Nesse momento, a mídia aparece como objeto de estudo privilegiado das ciências que estudam a educação.

\section{Justificativa do objeto de pesquisa}

A pesquisa que empreendemos durante o primeiro semestre de 2001 teve como objeto as distintas percepções ${ }^{6}$ de mensagem publicitária (refrigerante Sukita) por alunos de segundo ano de Ensino Médio ${ }^{7}$ durante exposição e debate em sala de aula. ${ }^{8}$ Esse estudo teve como objetivo primeiro a verificação da pertinência do uso de uma publicidade como suporte pedagógico para discussão de um tema transversal.

A opção pela publicidade como objeto de pesquisa em comunicação e educação se deve, de um lado, à óbvia relevância da mesma como produto da indústria cultural veiculado pela mídia e, de outro, ao relativo ineditismo de uma pesquisa com esse objeto na área de comunicação e educação. ${ }^{9}$

Assim, o "preconceito" em relação a uma abordagem científica do fenômeno da publicidade ${ }^{10}$ e a crença do senso comum em seus efeitos incontroláveis de persuasão e manipulação denunciam a relevância científica de uma pesquisa sobre publicidade na linha de comunicação e educação.

Elencamos, abaixo, as escolas visitadas, ${ }^{11}$ bem como as datas das coletas de dados:

Colégio Sion - 19/03/01 (São Paulo)

Colégio Canadá - 18/04/01 (Santos)

Colégio Senai - 10/04/01 (Santos)

Instituto Adventista de Ensino - 12/04/01 (São Paulo)

Escola Espiritualista Ordem e Progresso - 17/04/01 (Santos)

Colégio Presidente Kennedy - 10/04/2001 (Santos)

Colégio Treinasse - 16/04/01 (Santos)

Colégio Leão XIII - 11/09/01 (Santos)

Ateneu Santista - 09/04/01 (Santos)

Colégio Santa Cecília - 11/04/01 (Santos)

Colégio Novo Milênio - 20/04/01 (Vitória)

A peça publicitária televisiva escolhida tem como produto o refrigerante Sukita. A cena exibida transcorre integralmente num elevador, com dois personagens: um homem e uma mulher, esta última aparentando bem menos idade. O primeiro carrega um saco de laranjas enquanto a segunda toma o refrigerante. Depois de deter o fechamento da porta, permitindo 
a entrada da mulher, o homem toma a iniciativa do diálogo. Comenta sobre a temperatura ("tá quente aqui"), sendo respondido laconicamente com uma interjeição confirmatória. Na seqüência, pergunta se a interlocutora mora há muito tempo no prédio. Obtém resposta idêntica. Numa terceira iniciativa, indaga: "Tá gostosa a Sukita?", recebendo pela terceira vez a mesma resposta.

No momento em que parecia propor uma quarta questão, foi abruptamente interrompido com a frase: "Tio, aperta o vinte".

Neste momento o ruído da lata indica que o refrigerante terminou e ouve-se $o$ slogan: "Quem toma Sukita não engole qualquer coisa".

Esta peça está discriminada no Anuário do Clube de Criação, foi objeto de discussão na agenda pública e encerra um modelo de relação afetiva, em função do qual a abordagem exibida dentro do elevador foi deslegitimada. Esses fatores favoreceram um engajamento imediato, por parte dos alunos, na discussão de todos os universos amostrais pesquisados, justificando assim a escolha desta peça publicitária.

Apresentaremos, na primeira parte do nosso trabalho, o desenho metodológico da pesquisa, suas cautelas, limitações e fundamentações (I) e, na segunda parte, as conclusões verificadas nos seus distintos momentos (II).

\section{(I) Desenho metodológico da pesquisa}

A pesquisa que empreendemos foi desenhada em duas fases de aplicação e os critérios de categorização dos depoimentos foram sendo aperfeiçoados ao longo da coleta de dados (visitas às escolas). Discutiremos, assim, num primeiro momento o procedimento de coleta dos dados $(A)$ e, na seqüência, a classificação e análise dos mesmos (B).
(A) A coleta dos dados: duas fases de aplicação

A verificação, através da investigação que empreendemos, da pertinência ou não do uso da referida peça publicitária como suporte pedagógico se objetivou no contraste dos resultados obtidos em duas situações distintas de investigação. $\mathrm{Na}$ primeira fase desta pesquisa, o aluno foi estimulado a falar o que pensa da publicidade da forma mais livre possível. Os limites dessa possibilidade foram dados pelas condições materiais específicas de elaboração discursiva próprias ao quadro de uma manifestação em sala de aula. Todo ato de enunciação atualiza e objetiva a posição ocupada pelo enunciador e é, em grande medida, determinado por ela. Incidem, portanto, sobre esse ato, desde as disposições estruturais incorporadas durante a trajetória social de quem enuncia (habitus de classe, habitus profissional,...) até as condições materiais circunstanciais do momento do ato de fala.

Nesta primeira fase da pesquisa, foram condições materiais determinantes aos discursos do aluno, de um lado, a presença dos pesquisadores e dos instrumentos de pesquisa (gravador, televisão, vídeo, papel para anotações) e de outro, a dos colegas em sala de aula, num espaço destinado à educação formal. Soma-se a esses fatores o limite de tempo imposto ao conjunto da aplicação da pesquisa, de 60 minutos em cada universo escolar pesquisado.A proposta pedagógica apresentada procurava, nessa primeira fase da pesquisa, identificar a adesão do aluno pesquisado ao modelo de casal implicitamente proposto pela peça publicitária. Esse grau de adesão foi estudado em função das variáveis: sexo, escola, momento de intervenção no debate, estrutura e léxico do discurso.

$\mathrm{Na}$ segunda fase da pesquisa, o discurso dos alunos, registrado e analisado, foi antecedido de intervenção por parte do pesquisador. Esta intervenção 
questionava o modelo de casal proposto pela publicidade e a desautorização da abordagem do elevador. O objetivo foi avaliar o efeito deste questionamento nos discursos que se seguiram.

\section{A manifestação dos alunos}

$O$ aluno do segundo ano do ensino médio, pertencente aos nossos universos amostrais $^{12}$, manifestou-se verbalmente, através de um debate realizado em sua sala de aula e, por escrito, em casa, em redação solicitada pelo coordenador do curso. A manifestação verbal foi registrada de duas formas: gravação (discursos enunciados publicamente) e conversas interpessoais registradas por escrito por um dos pesquisadores espalhados pela classe.

O debate realizou-se, sempre, na sala de aula do aluno, isto é, no seu hábitat pedagógico. Desta forma, os alunos não foram deslocados para a realização da pesquisa. Os instrumentos necessários, como televisão e vídeo, foram trazidos para a sala de aula. Esta precaução metodológica visava a reduzir a artificialidade das condições de produção discursiva do aluno e aumentar as suas garantias simbólico-securitárias. ${ }^{13}$

Após uma exposição por duas vezes da peça publicitária ${ }^{14}$, o debate era sugerido por intermédio da pergunta: "O que vocês acharam da publicidade? Podem falar numa boa. O objetivo da pesquisa é saber o que vocês realmente pensam, sem muitas preocupações com acertos e erros" ${ }^{\prime 15}$. Assim, toda a explicação dos procedimentos da pesquisa foi feita tentando a aproximação léxica e de estilo com o discurso dos alunos. Saliente-se que a cordialidade, o engajamento com a proposta e o respeito dos procedimentos do debate foram observados em todos os universos pesquisados.

Esses procedimentos decorrem da preocupação de prever e reduzir os efeitos indesejados produzidos pela intrusão que sempre representa, para os alunos, a presença de um elemento externo à rotina escolar. A intensidade desses efeitos perversos, relativos à violência da ruptura simbólica, depende do ineditismo da aplicação de uma pesquisa acadêmica nos universos escolares específicos e da maior ou menor distância social entre o professor universitário (entrevistador) e os alunos ${ }^{16}$.

Assim, a título de exemplo, o intervalo de tempo silencioso, de hesitação, entre a proposta definitiva do debate por parte do pesquisador e a primeira intervenção de um aluno, bem como o intervalo de tempo médio entre as intervenções, variaram em função destes fatores.

\section{Gravação e Transcrição}

Os discursos foram registrados em dois gravadores portáteis ${ }^{17}$. $O$ aluno que desejasse falar manifestava-se através de um aceno de mão e um dos pesquisadores se deslocava até o local onde ele estava sentado. $O$ uso de dois gravadores, encurtando os deslocamentos dos pesquisadores, justificou-se em função da tentativa de redução do tempo entre a manifestação do aluno e o registro do seu discurso.

Quando dois ou mais alunos levantavam a mão, eram convidados jovialmente a aguardar a sua vez. "Segura aí, meu, que eu já tô chegando". Ou: "Pessoal, se liga que não dá pra falar todo mundo junto". As intervenções foram transcritas literalmente após cada visita. Manifestações sonoras não-verbais como risos, assovios e gritos registrados pelo gravador, também foram indicadas no texto. Estas cautelas metodológicas facilitaram o trabalho de definição das categorias de análise, bem como a classificação dos depoimentos.

(B) Análise dos dados 
A metodologia qualitativa empregada levou-nos a um enfoque indutivo de análise dos dados. Sem partir de hipóteses estabelecidas a priori, não tínhamos por que buscar dados ou evidências que as confirmassem ou as negassem. Tomamos, como ponto de partida, focos de interesse amplos como o uso da mídia em sala de aula, a reação a uma mensagem publicitária como objeto de discussão pedagógica e a pertinência do uso desta mensagem como suporte pedagógico para discussão de temas transversais em sala de aula.

A análise que propomos neste trabalho foi sendo construída ao longo da coleta de dados. Assim, imediatamente após cada visita, os discursos registrados eram transcritos e examinados. Desta forma, as intervenções dos alunos foram sendo agrupadas ao longo de cada coleta ${ }^{18}$. Os critérios desta aproximação converteramse em categorias de análise ${ }^{19}$. Observese que estas categorias que permitiram a classificação de todas as intervenções ao longo da pesquisa foram identificadas desde a análise de dados coletados na primeira escola visitada (Colégio Sion) ${ }^{20}$.

As intervenções dos alunos foram classificadas, inicialmente, em função da sua incidência, em "opinião dominante" e "opinião dominada".

A "opinião dominante" desautoriza a abordagem do homem no elevador, enquanto que a opinião dominada, embora reconheça a existência de um modelo socialmente aceito e esperado de abordagem erótico-afetiva, admite a contingência, isto é, a possibilidade de outros modelos sem condenação moral.

Dentro da categoria "opinião dominante", discriminamos quatro subcategorias: a primeira delas reúne as intervenções que relacionam diretamente o consumo com as categorias sociais "velho" e "jovem"; a segunda reúne as intervenções que relacionam a estas mesmas categorias outros comportamentos; a terceira reúne os discursos que vinculam as categorias "velho" e "jovem" ao capital estético e a quarta, os discursos que vinculam essas categorias ao capital econômico.

As unidades de intervenção dos alunos, classificadas em função das categorias citadas, eram identificadas por três informações suplementares: o sexo do aluno, a escola em que estuda e o momento da interferência no debate.

Este momento foi objetivado pela identificação da ordem de intervenção (do primeiro aluno a se manifestar, segundo, terceiro, até o último).

Assim, vistas as condições materiais de elaboração da pesquisa, bem como as cautelas metodológicas tomadas, passamos à análise dos enunciados propostos pelos alunos em função das categorias mencionadas.

(II) A análise dos enunciados

Como o nosso principal objetivo era analisar a pertinência do uso da publicidade para a discussão do tema transversal (discriminação em função da idade), bem como o papel do professor na condução do debate, apresentaremos os resultados da pesquisa em função da intervenção do professor. Num primeiro momento, são analisadas as manifestações dos alunos anteriores a essa intervenção (II.A) e, num segundo momento, as posteriores (II.B).

(II.A) Conclusões da primeira fase da pesquisa - o discurso sem intervenção

"Velhice" e "juventude" são categorias sociais, isto é, suas fronteiras constituem objeto de luta em cada universo social.

Desta forma, essas categorias não são dadas, necessárias ou da natureza das coisas, mas são construídas socialmente.

A relação entre idade social e idade cronológica é complexa. Cada campo social tem suas regras próprias de envelhecimento. Entendemos esse campo como um espaço de posições sociais que 
se definem umas em relação às outras. Essa interdependência de posições e de distâncias entre essas posições autorizanos a pensar um campo dentro da lógica sistêmica. Assim, enquanto sistema de posições definidas reflexivamente ${ }^{21}$, todo campo pressupõe o contraste entre postos complementares: comandantes e comandados, vedetes e obscuros, vencedores e derrotados, ricos e pobres e, também, "jovens e velhos". Daí, afinando a análise, podemos concluir que um espaço social é um sistema de diferenças, um sistema de posições que se definem pela sua própria oposição, como os pontos cardeais se definem em relação aos seus opostos.

As fronteiras simbólicas que separam categorias sociais como "jovens" e "velhos" são interiorizadas reflexivamente.

Neste sentido, mensagens que apresentam representantes categoriais devidamente contrastados em relação a seus referenciais antagônicos são mais imediatamente percebidas ${ }^{22}$. É o caso da publicidade, objeto de nossa pesquisa ${ }^{23}$. A indignação face à abordagem do elevador advém do contraste e não desta ou daquela idade presumida substancialmente.

As oposições consagradas terminam por parecer inscritas na natureza das coisas. No entanto, qualquer exame crítico, ainda que superficial, sobretudo se armado com o conceito de campo, levanos a descobrir que, com muita freqüência, cada uma das oposições não tem nenhum conteúdo sem o contraste com a posição antagônica, em relação à qual ela, em muitos casos, só representa a inversão racionalizada. É o caso de numerosas oposições que estão em vigor hoje nas ciências sociais: indivíduo e sociedade, consentimento e conflito, consenso e coação. De maneira mais evidente ainda as divisões em "escolas", "movimentos" ou "correntes": "estruturalismo" e "construtivismo", "modernismo" e "pósmodernismo", tantos rótulos com aparência conceitual, mas sem autonomia em relação a seus opostos ${ }^{24}$.

Esse ponto de vista relacional permite corrigir equívocos nominalistas que fazem crer na existência de uma posição social (um papel, um posto, uma função, um cargo, etc.) por elas mesmas, independentemente das posições que Ihe são complementares e que definem reflexivamente seus limites no espaço. Esse nominalismo essencialista também cristaliza as posições sociais em função da permanência de suas nominações. Assim, a alcunha de diretor definiria uma posição social independentemente da relação de forças a que se submete o circunstancial ocupante desde posto e que define a permanente redistribuição do poder no espaço social considerado, isto é, do capital específico em circulação neste espaço. São a concentração e a escassez deste capital específico que permitem a avaliação das distâncias sociais no interior de cada campo.

Desta forma, toda iniciativa de classificação social por idade, envolvendo essas categorias, representa um golpe de violência que se inscreve neste quadro de luta com graus distintos de oficialidade. A idade é um dado biológico socialmente manipulado e manipulável. As pesquisas de marketing, de opinião pública em geral, os cadastros públicos e privados são exemplos desta permanente tentativa, socialmente interessada, de tornar cronológico um critério que distingue categorias referenciais, autopoiéticas, isto é, que só podem existir uma em relação à outra.

A publicidade participa desta luta social, historicamente constituída, pela definição legítima do "jovem" e do "velho", impondo como critério o consumo. Este último se relaciona aos modos socialmente estruturados que permitem o uso dos objetos para demarcar categorias sociais. Esta relação entre estratégias de consumo e categorias sociais é apontada por Appadurai $^{25}$, para quem o valor não é concebido como uma propriedade dos 
objetos, mas é definido em função do uso social que dele faz o consumidor. Mas é Bourdieu quem associa com mais clareza o consumo a um capital social específico, isto é, a um grau de reconhecimento social, de pertencimento e discriminação, de definição, em suma, das fronteiras simbólicas entre este e aquele grupo social ${ }^{26}$.

Uma breve análise histórica nos permite constatar que as fronteiras da juventude e da velhice nem sempre foram definidas em função dos mesmos critérios. Assim, Skinner observa que no século XVI, em Florença, o critério de distinção legítimo entre "jovens" e "velhos" era a virilidade, a capacidade de agir violentamente.

Desta forma, os velhos reservavam para si a sabedoria, decorrente de uma trajetória de vida mais longa e, portanto, o poder decisório na cidade ${ }^{27}$. Na Idade Média, George Duby mostra como os limites da juventude eram manipulados pelos detentores do patrimônio para que os jovens permanecessem em estado de irres ponsabilidade e não pretendessem, assim, a sucessão e o acesso à herança ${ }^{28}$.

Ao participar da luta social pela categorização, nomeação e discriminação dos fenômenos, a publicidade também participa dos múltiplos e contraditórios mecanismos de definição social da realidade. Ao propor e impor formas particulares de visão e de divisão do mundo, a publicidade age por golpes ininterruptos de violência simbólica, oferecendo à sua audiência significados interligados, caminhos de sentido que, sem dúvida, facilitam ou, por vezes, possibilitam a atribuição de algum sentido ao real. A eventual identificação, por parte do aluno, deste efeito da mensagem publicitária constitui-se em indagação primária de nossa pesquisa.

A análise das categorias propostas permite-nos concluir que 0 aluno, espontaneamente, associou um determinado comportamento de consumo à categoria social do "velho" e outro tipo de "consumo" à categoria social da "jovem". Assim, intervenções como: "O cara era tão velho que ainda tomava suco de laranja. Hoje em dia já tem um monte de refrigerante. Ele ainda tomando suco de laranja invés de tomar Sukita." (Escola Treinasse); "Ele com a laranja mostra que está mais velho, ultrapassado, e ela com a Sukita já é a nova." (Colégio Leão XIII); "O comercial tá querendo dizer que laranja é coisa pra velho. Quem quiser agora toma Sukita, não uma laranja." (Colégio Leão XIII); "Bebe Sukita e você vai ser gostosa, e tome laranja, você vai ser um velho babão quando você crescer." (Colégio Sion); são reveladoras dessa associação.

A aproximação das categorias "velho" e "jovem" a um certo consumo vem acompanhada de associações subsidiárias como o capital estético dos protagonistas. Algumas intervenções são contundentes e reveladoras: "O bagulho feião. O bagulho de velho mesmo." (Leão XIII); "E a carinha do velho, cheio de pé-de-galinha." (Colégio Canadá); "Se o cara fosse o Raí e estivesse segurando um saco de laranja, com certeza ela daria bola." (Leão XIII); "Eu acho que não tinha nada a ver com a idade. Era o cara mesmo. Se fosse um coroa bonitão, sei lá...Ela podia até ouvir." (Presidente Kennedy).

Além do capital estético, também o capital econômico foi destacado como elemento de definição categorial. Assim, as aspirações de gerações sucessivas são constituídas em relação a estados diferentes da estrutura da distribuição dos bens e das chances de obter esses diferentes bens: o que para os pais era um privilégio extraordinário tornou-se, estatisticamente, banal. Desta forma, muitos conflitos entre gerações são sistemas de aspirações constituídos em idades diferentes.

Algumas intervenções exemplificam essa associação: "E no caso do empresário Roberto Justus? Ele é atualizado, é rico e é empresário." (Colégio Canadá); "As meninas estão atrás de velho rico."(Colégio 
Canadá); "Se o cara chega com uma Ferrari, vamos ver se ela não ia dar bola para ele." (Colégio Leão XIII); "E tem muito velho rico desfilando com carro importado do ano, uma puta loira do lado. Só que na hora do vamos ver, não levanta nem..." (Colégio Canadá); "Um mendigo pode ter um papo até a ponta do dedão do pé dele, mas ele não cata ninguém." (Colégio Canadá); "Eu não tenho preconceito nenhum entre uma mulher mais velha namorar um cara mais novo; é só ter grana; se alguma de vocês estiver a fim..." (Colégio Treinasse); "Eu acho que por ele ser mais velho, ele deve ter uma conta meio gordinha, e ela deve ter se interessado." (Instituto Adventista de Ensino - IAE).

A associação do consumo com as categorias "velho" e "jovem" não esgota a análise da ação na peça publicitária proposta.

Desta forma, outros elementos comportamentais são destacados como distintivos dessas categorias: "Quanto mais velho mais idiota." (IAE); "As meninas podem até ficar com medo dos velhos com esse comercial." (Ateneu Santista); "O velho foi safado e ela entrou provocando com o canudinho." (Colégio Canadá); "Aquele sorriszinho sarcástico de velho, sadomasoquista." (Colégio Canadá); "Se fosse uma velha de 70 anos, toda caída, ele não ia querer fazer isso com ela, ou ia?" (Colégio Canadá); "A menina maior inocente e o tiozinho, maior pedófilo." (IAE); "Tem velho que é tarado assim. Eles são convencidos." (IAE); "Ele tem que ficar com as mulheres da idade dele, tem que ser casado." (IAE).

Se as intervenções condenatórias da abordagem no elevador tiveram maior incidência ("opinião dominante"), alguns alunos dos mesmos universos amostrais entrevistados manifestaramse contrariamente ("opinião dominada"). A incidência destas intervenções, que de alguma forma contestaram a representação definida pela peça publicitária, concentrouse no segmento masculino do universo amostral. Isso se deve, em parte, a um processo de transferência psicológica de identificação ${ }^{29} \mathrm{com}$ os personagens da trama, que se verificou tanto do lado das alunas em relação à "jovem" como do lado dos alunos, em menor escala, em relação ao homem.

Assim, a imigração mental do mundo da sala de aula para o elevador da cena exibida (uma outra intriga com outros personagens num outro contexto e num outro cenário) requer implicação, empatia e identificação. Separação com o mundo real, a evasão proporcionada pela recepção da publicidade é, na verdade, uma inserção no "mundo da trama", uma identificação com os personagens. É por isso que essa evasão requer, se não a concordância, pelo menos um acordo entre os esquemas de percepção que organizam a ficção (os esquemas de interpretação e de ação dos personagens) e os do receptor.

Esse processo psicológico de identificação é claramente objetivado em algumas das declarações registradas: "Magina um cara destes tentando me agarrar no elevador. Que nojo!"(Colégio Sion); "Se eu levasse uma cantada que nem a desse homem, eu faria a mesma coisa. Poxa, já pensou eu dentro de um elevador sozinha e vem um indivíduo como este tentar me agarrar?" (Escola Espiritualista Ordem e Progresso); "Quando eu tiver a idade dele eu também vou fazer isso. Mas eu vou conseguir a menina." (Colégio Canadá); "Tinha que colocar eu para fazer esse comercial e não ele." (Senai).

As intervenções, integrantes da categoria "opinião dominada", além de se concentrarem no segmento masculino da amostra, também foram prioritariamente enunciadas nos primeiros momentos dos debates. Assim, quase todas ocorreram entre as cinco primeiras manifestações registradas em cada debate.

Isto é, à medida que se definia o "clima de opinião" na classe, as intervenções desviantes tendiam a rarear. Por isso, quanto mais nítida era a opinião da maioria, 
menos provável era uma intervenção no sentido contrário ${ }^{30}$. Esse fenômeno já fora denunciado pela pesquisadora Elisabeth Neumann no modelo da "Espiral do silêncio" ${ }^{31}$. O desconforto psicológico decorrente do ônus social de assumir publicamente uma opinião minoritária acarreta uma tendência estatística ao silêncio em meio aos partidários desta opinião. Ora, se a opinião já era minoritária, esse silêncio de uma parcela significativa de seus defensores a torna ainda mais minoritária. Esta perspectiva progressiva, também constatada em nossa pesquisa, justifica o nome dado pela pesquisadora: "espiral".

Selecionamos algumas intervenções inscritas na categoria "opinião dominada", ou seja, que espontaneamente criticaram o modelo de abordagem implicitamente sustentado pela peça publicitária: "O amor não tem idade. Não tem nada a ver." (IAE); "O senso comum é uma pessoa nova com uma pessoa nova. É o que a sociedade impõe." (Colégio Presidente Kennedy); "As mulheres mais velhas pegam modelos de 18 ou 19 anos. E por que o cara não pode?" (Colégio Senai);

"Eu acho o seguinte: a maioria da meninas de hoje, elas fazem isso automaticamente. Elas gostam de ser maltratadas. Elas preferem um novo, que pouco sabe da vida, que vive de dizer gírias ou palavrões, do que uma pessoa mais velha, que oferece um papo mais interessante devido a experiências anteriores, onde aprendeu a se portar com mais elegância e educação." (Colégio Presidente Kennedy);

"A idade não tem nada a ver. Não é a idade que conta e sim o sentimento." (Colégio Presidente Kennedy); "Eu acho que a idade não influencia em nada." (Ateneu Santista); "A sociedade tem culpa nisso, porque a maioria das pessoas namoram pessoas da mesma faixa de idade." (Ateneu Santista).

Assim, se durante a fase de "manifestação livre" estas foram as categorias preponderantes, aqui explicitadas apenas por alguns exemplos, as manifestações dos alunos posteriores à intervenção do pesquisador revelam a pertinência das categorias, mas indicam, como veremos a seguir, uma reversão quantitativa das tendências.

(II.B) Conclusões da segunda fase da pesquisa - o discurso após a intervenção

A cisão entre a primeira e a segunda fase da pesquisa foi marcada pela intervenção do pesquisador. Apresentado como tal e como professor universitário pelo coordenador ou diretor pedagógico do ensino médio, o pesquisador, ao intervir, fazia-o na condição de um porta-voz legítimo ${ }^{32}$.

O momento da intervenção, em torno de 20 minutos após o início do debate, procurava dividi-lo em duas etapas com duração semelhante. Tomamos a cautela de questionar a opinião dominante, respeitando a seqüência lógica das intervenções. Essa medida visava a reduzir - caráter de ruptura formal inerente a qualquer intervenção dessa natureza e colocar em evidência a ruptura conceitual do questionamento.

Assim, a título de exemplo, no Colégio Sion, interviemos após comentário que desautorizava o uso de "malhas sobre os ombros" por um "puta velhão". Observamos: "Eu não sabia que não estava autorizado a usar malha sobre os ombros". No Instituto Adventista de Ensino, perguntamos se "existe uma idade certa para xavecar". Na escola Novo Milênio, após observação sobre a "agressão sexual" sofrida pela jovem no elevador, perguntamos em tom cândido: "Então, comentar sobre a temperatura no elevador e perguntar se a Sukita está gostosa é uma 
agressão sexual?"

Embora o senso comum sempre busque uma racionalização a posteriori para os comportamentos, uma análise menos ingênua permite-nos concluir que grande parte das manifestações subjetivas são espontâneas, isto é, escapam à lógica de um cálculo estratégico custo $\mathrm{x}$ benefício. Isso porque as instâncias de socialização exercem sobre o indivíduo uma ação pedagógica multiforme, fazendo-lhe adquirir saberes práticos indispensáveis ao ajuste entre comportamentos e expectativas. Assim, o questionamento proposto tinha como objeto uma representação legítima de abordagem socialmente aprendida e interiorizada em uma trajetória de experiências semelhantes.

Como observa Schaff, "não é arbitrário o conteúdo desta aquisição, visto que as experiências das gerações passadas contêm em si uma soma determinada de conhecimento objetivo do mundo, sem a qual o homem não poderia adaptar a sua ação ao seu meio ambiente e não poderia subsistir enquanto espécie. Aprendendo ao mesmo tempo a falar e a pensar, assimilamos essa aquisição de uma maneira relativamente fácil; não temos que redescobrir constantemente a América, o que tornaria impossível todo o progresso intelectual e cultural ${ }^{33}$.

À medida que as experiências constitutivas do aprendizado social se repetem, acumulando-se, os traços que deixam cada uma delas se sobrepõem, combinam-se, reforçam-se, interiorizandose cada vez mais profundamente, transformando-se em disposições gerais e naturalizadas. Isto é, a repetição de uma situação diante da qual aprendemos a distinguir um comportamento legítimo de outros ilegítimos (socialmente reprováveis) gera uma tendência. Assim, sem necessitarmos de uma orquestração consciente das vantagens e desvantagens sociais de cada comportamento possível, agimos de forma a reproduzir a ordem social, de acordo com as disposições interiorizadas.

Desta forma, os condicionamentos associados a uma classe particular de condições de existência produzem o habitus, sistemas de disposições duráveis, estruturas estruturadas predispostas a funcionar como estruturas estruturantes, isto é, enquanto princípios geradores e organizadores de práticas e de representações, que podem ser objetivamente adaptadas a seus fins sem supor o alcance consciente desses fins e o domínio expresso das operações necessárias para alcançá-los ${ }^{34}$. Esses esquemas de classificação do mundo social interiorizados durante toda a trajetória social do indivíduo "dizem tudo sobre o mundo antes que o vejamos", usam a experiência sensorial como confirmação ajustada às disposições do que pode e deve ser visto e que governam, com maior ou menor rigidez, nossa percepção (estereótipos) ${ }^{35}$.

Esse saber prático, espontâneo e interiorizado fundamenta-se num princípio de economia da práxis inevitável na vida cotidiana $^{36}$. Como ensina Agnes Heller, "cada uma de nossas atitudes baseiase numa avaliação probabilística. Em breves lapsos de tempo, somos obrigados a realizar atividades tão heterogêneas que não poderíamos viver se nos empenhássemos em fazer com que nossa atividade dependesse de conceitos fundados cientificamente"37.

De alguma maneira, o saber teórico das representações, adapta-se a um saber prático que lhe é anterior ${ }^{38}$. É a concordância entre as estruturas objetivas e as estruturas cognitivas, entre a conformação do ser e as formas do conhecer, entre o curso do mundo e as expectativas a seu respeito que tornam possível esta relação com o mundo que Husserl descrevia com o nome de "atitude natural" ou de "experiência dóxica", mas deixando de lembrar as condições sociais de possibilidade ${ }^{39}$. Esta experiência apreende o mundo social e suas divisões arbitrárias, a começar pela divisão 
socialmente construída entre os $\operatorname{sexos}^{40}$, como naturais, evidentes, e concentra, desta maneira, todo um reconhecimento de legitimidade ${ }^{41}$.

Assim, como observa Vitorino Sampaio, "mediante a projeção reiterada de representações e esquemas de comportamento, a publicidade promove uma espécie de tematização pública "invisível" de questões fundamentais, em que os sentidos da ação humana são tratados de forma naturalizada, como se não houvesse simplesmente alternativas de modelos e atitudes além daquelas anunciadas"42. Em função disso, o questionamento de um discurso construído com base em disposições incorporadas em condições semelhantes não pode se limitar a uma condenação ética por parte do educador. Cabe a este "des-moralizar" o estereótipo situando-o, para o aluno, como um facilitador cultural, socialmente construído, e questionável como tal.

A análise dos resultados da primeira e segunda fases da pesquisa permite-nos concluir que a intervenção, propondo uma reflexão sobre o estereótipo, produziu notáveis efeitos no discurso dos alunos. As categorias de "opinião dominante" e "opinião dominada" definidas na primeira fase inverteram-se. Isto é, a maioria dos que desautorizaram a abordagem do elevador num primeiro momento reconsiderou suas propostas. A título de exemplo: "Acho que não tinha nada a ver o que eu falei". (Colégio Sion); "Falei besteira, mas tudo bem. Valeu". (Colégio Santa Cecília). Outros relativizaram suas afirmações: "Acho que tá tudo bem as idades serem diferentes, mas o cara exagerou um pouco". (IAE). Ou reconheceram que, pelo menos em análises casuístas, as possibilidades de relação afetiva em relação às idades são mais amplas: "Neste caso é diferente. O senhor é conservadão, se cuida"43 (IAE).

Desta forma, podemos concluir pela pertinência da proposta pedagógica empreendida e pela necessidade de uma reflexão mais ampla sobre o papel do uso dos meios como suporte para discussão dos estereótipos em geral .

\section{Notas}

1 Projeto com a participação dos pesquisadores: Felipe Lopes, Felipe Melo e Vivianne Ferreira. Alunos de graduação da ESPM.

2 VERRET, M. Le temps des études. Paris, H. Campion, 1975.

3 VINCENT, G. L'école primaire francaise. Lyon, PUL, 1980.

4 Sobre a interiorização da "ordem das coisas" através da organização curricular, ler GRIGNOL, C. L'ordre des choses. Paris, Minuit, 1971.

5 FOULIN, J-N., MOUCHON, S. Psychologie de l'éducation. Paris, Nathan, 1998, p. 24.

6 Como observa Teotônio Simões, "assim como uma pessoa faz parte da obra, recriando-a, um telespectador também recria um comercial. $E$ as pesquisas estão aí para comprovar 0 fato de que muitas vezes as pessoas 'entendem' de forma diferente uma mesma peça publicitária". Publicidade e reflexão. In: Revista da ESPM, V.3, N. 1, 1996, p. 64.

7 A opção por este nível da hierarquia escolar (segundo ano do Ensino Médio) ateve-se à busca do máximo de maturidade presumida, e o obstáculo prático da preparação para o vestibular dos alunos de terceiro ano.

8 Para maiores esclarecimentos a respeito das implicações metodológicas de definição de objeto em pesquisa qualitativa sobre produtos da mídia, ler ALTHEIDE, D. L. Qualitative media analysis, Thousand Oaks, Sage, 1996.

$9 \mathrm{Na}$ área de comunicação e educação, os objetos mais freqüentes de estudo são relacionados à produção ficcional seriada. Sobre a abordagem curricular da propaganda, ler 0 artigo de Cláudia Lukianchuki, "Discurso da propaganda e diretrizes curriculares". In: Comunicação e Educação, n. 17, pp. 16-28.

10 Sobre este "preconceito", ler a Introdução da Sociologia 
da publicidade de Georges Lagneau, São Paulo, CultrixEdusp, 1981.

11 A escolha das escolas procurou contemplar os critérios laico/religioso, público/privado e políticas pedagógicas distintas dentro dos critérios acima.

12 Sobre a definição da amostra e o princípio da amostragem, ler BABBIE, E. Survey research methods. Belmont, Wadsworth, 1990; KISH, L. Survey Sampling, New York, John Wiley \& Sons, 1965; RAJ, D. The design of sample surveys, New York, McGraw, 1972.

13 A abordagem qualitativa empregada nesta pesquisa repousa nas bases operacionais da "Grounded theory". Para um aprofundamento desta proposta metodológica, ler CHENITZ, W. C., SWANSON, in "Qualitative research using grounded theory". In: CHENITS W.C., SWANSON, J. From practice to grounded theory; Menlo Park, AddisonWesley, 1986. pp. 91-101.

14 A exibição da peça por duas vezes foi decidida desde a primeira escola visitada em função da relativa desa-tenção dos alunos durante a primeira exibição.

15 A pergunta "O que vocês acharam da..." inscreve-se no quadro técnico de pesquisas semi-estruturadas como "Tell me about..." ou "What do (did) you think about ...?" indicado por BELENKY, M. F., CLINCHI, B. M., GOLDEBERGER, N. R. and TARULE, J. M. Women's ways of knowing: the development of self, voice and mind. New York, Basic Books, 1986.

16 Essa distância social pode ser medida pelo eixo público/ privado em que se categorizavam as escolas visitadas e, até mesmo, pelo valor da mensalidade, no caso das escolas particulares.

17 Sobre as técnicas de registro em ciências sociais, ler QUEIROZ, M. I. P. Variações sobre a técnica de gravador no registro de informação viva. São Paulo, T.A . Queiroz, 1991.

18 Comenta Arilda S. Godoy que "as abstrações são construídas a partir dos dados, num processo de baixo para cima". "Introdução à pesquisa qualitativa e suas possibilidades". In: Revista de Administração de Empresas - FGV. São Paulo, v. 35, n. 2, 1995, pp. 57-63.

19 Como observa Renata Tesch, "quando se concentram em descrição, as categorias são usadas para descobrir as comunalidades ou os constituintes de um fenômeno". In Qualitative research: analysis types and sotttware tools. New York, The Falmer Press, 1990, p. 73.

20 A análise dos dados coletados nas outras 10 escolas confirmaram a pertinência das categorias propostas. Assim, os dados coletados nestas escolas não justificaram, em momento algum, a criação de uma nova categoria. Por isso, qualquer novo dado coletado foi transcrito e imediatamente classificado em função dessas categorias.

21 Sobre o conceito de espaço social como sistema, ler ACCARDO, A. Introduction à une sociologie critique. Bordeaux, Le Mascaret, 1997, p. 44.

22 Como observa Nelly de Camargo, "a mensagem publicitária recorre com freqüência a pares de antônimos para causar impacto e ressaltar o valor do objeto". "O léxico da publicidade". In: Revista da Intercom, XVIII, n. 1, 1995, p. 16.

23 Uma abordagem crítica aos efeitos persuasivos da publicidade e proposta por Jean Baudrillard em "Significação da publicidade". In: E COSTA LIMA, L. Teorias da comunicação de massa, São Paulo, Paz e Terra, 1990, pp. 291-199. Para uma sistematização das abordagens críticas à publicidade, ler o capítulo "Criticisms of advertising". In: Social communication in advertising, LEISS, W., JHALLY, S. London, Routledge, 1997, pp. 1533.

24 BOURDIEU, P. Méditations pascaliennes, Paris, Seuil, 1997, p. 121.

25 APPADURAI, A. The social life of things. Cambridge, Cambridge University Press, 1986.

260 conceito de capital está presente em grande parte da obra sociológica de Pierre Bourdieu. Para uma análise mais detalhada, ler La distinction. Paris, Minuit, 1979 e Le sens pratique. Paris, Minuit, 1980.

27 SKINNER, Q. Fundações do pensamento político moderno. São Paulo, Companhia das Letras, 2000.

28 DUBY, G. L' Europe au Moyen-âge. Paris, Flammarion, 1984. 
29 "A identificação produz-se quando o espectador assume emotivamente o ponto de um personagem, ao considerálo um reflexo da sua própria situação de vida ou de seus sonhos/idéias". em FERRER, J. A televisão e a escola. Porto Alegre, Artes médicas, 1996. p. 36.

30 Observe-se que esta tendência só se verificou entre as manifestações assumidas perante a classe, isto é, as submetidas à apreciação e controle do grupo. As manifestações não assumidas perante a classe (anotadas pelos pesquisadores) revelam que a "opinião dominada" persistiu, mas seus defensores não ousavam sustentá-la perante 0 coletivo.

31 NOËLLE-NEUMANN, E. "The spiral of silence: a theory of public opinion", in Journal of Communication, v. 24. 1974. pp. 43-51. No Brasil, o modelo da espiral do silêncio vem sendo pesquisado em divulgado por Antonio Hohlfeldt. Ler 0 artigo "Hipóteses contemporâneas de pesquisa em comunicação", In: Teorias da comunicação. Petrópolis, Vozes, 2001, pp. 187-240.

$32 \mathrm{Na}$ maioria das escolas visitadas, o pesquisador foi apresentado como docente de faculdades "destacadas", "top de linha", "primeiras no ranking" na área de comunicação e modelares no ensino da publicidade e do jornalismo. Este discurso, que tem como efeito imediato a transferência do capital institucional acumulado no campo das faculdades de comunicação para a pessoa do pesquisador, potencializou a legitimidade de qualquer intervenção por parte deste último.

33 SCHAFF, A. Linguagem e conhecimento. Coimbra, Almedina, 1974, p. 251.

34 BOURDIEU, P. Le sens pratique. Paris, Minuit, 1980, p. 88.

35 Sobre os estereótipos, ler o clássico LIPPMANN, W. Public Opinion. Nova York, Free Press Paperbacks, 1997, pp. 53- 100.

36 Num primeiro momento, e contrariamente às instigações de Lippmann, os psicólogos sociais americanos insistiram no caráter redutor e nocivo do estereótipo. Eles 0 colocaram sob o signo do pejorativo, permanecendo, assim, fiéis à acepção comum do termo. À medida que 0 estereótipo advém de um processo de categorização e de generalização, ele simplifica o real; ele pode assim favorecer uma visão esquemática e deformada do outros que acarreta preconceitos. É nesse sentido que vão, até hoje, numerosas tentativas de definição.

37 HELLER, A . 0 cotidiano e a história. São Paulo, Paz e Terra, 1970, p. 44.

38 Sobre a anterioridade dos esquemas socialmente interiorizados em relação às representações cognitivas derivadas da percepção sensorial, poderíamos refutar a tese afirmando que qualquer percepção sensorial posterior e dissonante com os esquemas mentais preexistentes seria decisiva para eliminá-los e substituí-los. 0 que nós percebemos, no entanto, já está, desde 0 início da percepção, modelado pelas imagens coletivas que temos na cabeça: nós vemos, dizia Lippmann, o que nossa cultura definiu previamente para nós. 0 que confirma, de maneira eloqüente, uma pesquisa aplicada em uma classe durante a qual exibia-se a crianças brancas uma foto com uma bela propriedade. Depois de lhes ser retirada a foto, era-lhes perguntado o que fazia a mulher negra na casa. Um grande número respondeu que ela a limpava, quando, na realidade, não havia na foto nenhum negro (KLINEBERG, O. Psychologie sociale, PUF, 1963).

39 A "experiência dóxica" designa as imagens na nossa cabeça que mediatizam nossa relação com 0 real. Tratase de representações feitas, de esquemas culturais preexistentes, com a ajuda dos quais cada um filtra a realidade ambiente. Segundo Lippmann, essas imagens são indispensáveis para a vida em sociedade. Sem elas, 0 indivíduo permaneceria mergulhado no fluxo e refluxo da sensação pura; ser-the-ia impossível compreender 0 real, categorizá-lo ou agir sobre ele. Como, com efeito, examinar cada ser, cada objeto em sua especificidade própria e em detalhe, sem servir-se de um tipo ou uma generalidade? Tal procedimento seria, diz Lippmann, no rápido curso da existência, praticamente fora de cogitação.

40 Assim, uma pesquisa aplicada na França, na década de 60 , sobre a imagem da mulher, mostra que nos meios favorecidos ainda há tendência a considerar que um ensino muito puxado desvia a menina do papel que sua natureza lhe leva a ter, a saber, o lar e a educação das crianças (M. J. et P. H. Chombart de Lauwe et al. La femme dans la société. Paris, CNRS, 1963). Aderindo ao estereótipo, escolhemos para as meninas uma formação que leva a reproduzi-lo. É segundo a mesma lógica do 
ciclo vicioso, ou da profecia que provoca sua realização, que os membros dos grupos estigmatizados acabam se conformando com a imagem desvalorizada que Ihes confere 0 meio hostil. Interiorizando 0 estereótipo discriminante, eles são levados a ativá-lo no seu próprio comportamento.

41 BOURDIEU, P. La domination masculine. Paris, Seuil, 1998, p. 14.

42 VITORINO SAMPAIO, I. S. Televisão, publicidade e infância. São Paulo, Annablume, 2000, p. 273.

43 Referindo-se ao interlocutor/pesquisador. 